\title{
Influence of aquatic exercises in physical condition in patients with multiple sclerosis
}

Felipe J. AIDAR 1,2,3*, Dihogo GAMA de MATOS ${ }^{3}$, Raphael F. de SOUZA ${ }^{1}$, Aline B. GOMES ${ }^{3}$, Francisco SAAVEDRA ${ }^{4}$, Nuno GARRIDO ${ }^{5}$, André L. CARNEIRO 6, Victor REIS 5

\begin{abstract}
${ }^{1}$ Department of Physical Education, Federal University of Sergipe, São Cristóvão, Brazil; ${ }^{2}$ Brazilian Paralympic Academy, Brazilian Paralympic Committee, Brasilia, Brazil; ${ }^{3}$ Department of Studies and Research in Performance, Sport, Health and Parasports, Federal University of Sergipe, São Cristóvão, Brazil; ${ }^{4}$ Department of Sports Science, Exercise and Health of the Trás-os-Montes e Alto Douro University, Vila Real, Portugal; ${ }^{5}$ Sport Research Centre, Health and Human Development (CIDESD), University of Trás-os-Montes and Alto Douro, UTAD, Vila Real, Portugal; 'State University at Montes Claros (UNIMONTES), Montes Claros, Brazil
\end{abstract}

*Corresponding author: Felipe J. Aidar, Cidade Universitária Prof. José Aloísio de Campos, Av. Marechal Rondon, s/n Jardim Rosa Elze, 49100-000, São Cristóvão, Sergipe, Brazil. E-mail: fjaidar@gmail.com

\section{A B S T R A C T}

BACKGROUND: Multiple sclerosis (MS) is a disabling chronic disease of the nervous system in which the myelin system of the central nervous system is deteriorated. This study aimed to evaluate the effectiveness of an aquatic exercise program on the physical condition of patients suffering from multiple sclerosis.

METHODS: The study included 26 participants divided into two groups: an experimental group (EG) with 13 individuals and a control group (CG) also with 13 individuals. The EG underwent 12 weeks of aquatic exercise, three times per week and $45-60$ minutes per session. The groups were evaluated pre- and post-intervention, and were later compared to check for differences between groups. Data was collected by using functional tests such as the Timed "Up and Go" Test, the Timed 7.62 Meters Walk Test, the Getting up from a Sitting Position Test and the Balance Test.

RESULTS: Significant differences were found between the groups in the post-intervention stage. Furthermore, significant differences were also observed in all domains of physical condition of EG patients, in the post-intervention stage. Results obtained from the intention-to-treat analysis were consistent with those found in the literature.

CONCLUSIONS: Therefore, this study's results suggest that aquatic exercise programs can effectively improve multiple sclerosis patient's physical condition and should be considered when coping with this public health problem.

(Cite this article as: Aidar FJ, Gama de Matos D, de Souza RF, Gomes AB, Saavedra F, Garrido N, et al. Influence of aquatic exercises in physical condition in patients with multiple sclerosis. J Sports Med Phys Fitness 2018;58:

Key words: Multiple sclerosis - Exercises - Physical fitness - Rehabilitation. DOI: $10.23736 /$ S0022-4707.17.07151-1)

M ultiple sclerosis (MS) is a chronic inflammatory disease of the central nervous system (CNS), which causes multifocal demyelination along with astrocytic gliosis and variable axon loss in the brain and spine. MS is one of the most common causes of nontraumatic disability in young adults and approximately 1-2.5 million people around the world are estimated to be affected, depending on the publication. 1,2

MS usually manifests itself between the age of 20 to
40 years, and rarely during childhood or in older ages. The disease course usually is a relapsing-remitting progression, with a transition to a secondary after some length of time, or a primary progression right from the start. The precise etiology of MS still remains unclear. ${ }^{2}$

MS currently has no cure and available treatments are offered to slow the progression of the disease, reduce relapses, or improve symptoms. ${ }^{3}$ Therefore, the symptomatic and supportive interventions that aim to 
improve daily functioning of patients with MS are important. ${ }^{4}$ Exercise training is considered an important behavioral strategy with significant implications for slowing MS progression. ${ }^{5}$

The American Physical Therapy Association has established preferred practice patterns that provide a basis for therapy exercises for patients, including those with MS. ${ }^{6}$ One specific type of physical therapy that is recommended by the American Physical Therapy Association is the aquatic exercise. The buoyant nature and viscosity of water facilitate physical activities for individuals with physical weaknesses. In addition, as patients with MS may experience exacerbated symptoms when exposed to heat, aquatic exercises can help reducing weakness and other neurologic symptoms. ${ }^{7}$

Notwithstanding, there is limited information about the types of physical activity performed by MS patients. 8,9 There is also little knowledge on the relationship between aquatic exercises and improved physical condition in patients with MS, in particular when assessed through tests of balance, walking, and lower limb strength.

Thus, this study aimed to evaluate the influence of aquatic exercises on physical condition, measured by walk, lower limb strength and balance tests, in patients affected by MS.

\section{Materials and methods}

\section{Sample}

The study began with 28 patients, divided randomly (by lottery) into two groups, both with 14 individuals each: the control group (CG) and the experimental group (EG). At the beginning of the second week of aquatic exercises, a patient from the EG withdrew from the program, leaving the EG with only 13 individuals. For the remainder of this study, no other patient left the program. However, an individual from the $C G$ failed the post-intervention physical assessment. Thus, at the end of the program, the EG was composed by 13 individuals, four males and nine females, whereas the CG was also composed by 13 individuals, but with five males and eight females, as seen in Table I.

The intervention was performed using the program called "New Horizons", developed by the Third Military Fire Battalion in Belo Horizonte, Minas Gerais, Brazil.
TABLE I.-Sample characteristics.

\begin{tabular}{lcc}
\hline & $\begin{array}{c}\text { Mean } \pm \text { SD } \\
\text { experimental group }\end{array}$ & $\begin{array}{c}\text { Mean } \pm \text { SD } \\
\text { control group }\end{array}$ \\
\hline Age (years) & $41.3 \pm 7.3$ & $43.6 \pm 7.6$ \\
Age (years) - male & $40.8 \pm 9.6$ & $44.5 \pm 8.0$ \\
Age (average \pm SD) - female & $41.6 \pm 7.6$ & $43.2 \pm 5.8$ \\
Gender (male/female) $(\%)$ & $4(30.1) / 9(69.9)$ & $5(38.5) / 8(61.5)$ \\
\hline
\end{tabular}

SD: standard deviation.

All subjects underwent a pre-test, after which the EG began aquatic exercise training. The control group did not participate in any prescribed physical training, as confirmed in the interviews conducted at the end of the intervention. All patients who participated in this study had previously received medical clearance to do so, and the eligibility criterion used was having been diagnosed with MS for over a year. All volunteers were informed about the study and signed the authorization form (informed consent) according to Resolution 466/2012 of the National Ethics Committee - CONEP, the National Health Council, in accordance with the ethical principles expressed in the Declaration of Helsinki (1964, reformed in 1975, 1983, 1989, 1996 and 2000), the World Medical Association.

Patients were classified according to Functional Systems and the Expanded Disability Status Scale (EDSS). 10 Thus, $15.4 \%$ of the EG individuals had mild disability (mild), 76.9\% had moderate disability and 7.7\% had high disability. Moreover, $23.1 \%$ of subjects belonging to the control group had mild disability (mild), $61.5 \%$ had moderate disability and $15.4 \%$ had high disability (Table II). No patients with serious disabilities (very high disabilities) were identified in this study.

\section{Instruments}

The aquatic exercises were performed in a $25 \mathrm{~m} \mathrm{x}$ $12.5 \mathrm{~m}$ unheated pool, with an average depth of $1.5 \mathrm{~m}$,

TABLE II.-Sample distribution according to EDSS by group and gender.

\begin{tabular}{lcc}
\hline & $\begin{array}{c}\text { Occurrence } \\
\text { experimental group }\end{array}$ & $\begin{array}{c}\text { Occurrence } \\
\text { control group }\end{array}$ \\
\hline Mild disability (male/female) $(\%)$ & $2(100) / 0(00)$ & $1(25) / 2(75)$ \\
Moderate disability (male/female) $(\%)$ & $3(30) / 7(70)$ & $2(25) / 6(75)$ \\
High disability (male/female) $(\%)$ & $0(00) / 1(100)$ & $1(50) / 1(50)$ \\
\hline
\end{tabular}

EDSS: Expanded Disability Status Scale

Mild disability: 0 to 3.0 ; moderate disability: 3.5 to 5.5 ; high disability: 6.0 to 7.5 ; very high disability: -8.0 to 10.0 (not addressed in the study). 
and the equipment used for the water activities included water dumbbells, buoys/floats and water noodles.

\section{Functional tests}

TIMED “UP AND Go” Test

The Timed "Up and Go" Test evaluates agility, strength and balance. In this test, the evaluator measures the time taken by an individual to stand up from a chair with armrests, walk three meters, turnaround, return to the chair and sit down. ${ }^{11}$ This is a practical test to measure lower limb function since it does not require special equipment or training from the evaluators.

\section{TIMED 7.62 METER WALK}

The Timed 7.62 Meter Walk Test is a measure of lower limb function present in the multiple sclerosis functional composite (MSFC). This instrument was developed in 1994 by the American Society of Multiple Sclerosis and is currently increasingly used in clinical studies involving people with MS. ${ }^{12}$ The test requires the patient to walk, as quickly as possible, a distance of $7.62 \mathrm{~m}$ (25 feet) to a previously marked point on a nonslippery floor. Each test consisted of two timed attempts and the patient was allowed to use any kind of support for walking if needed.

\section{GETTING UP FROM A SITTING POSITION}

This test is used to evaluate the functional capacity of the lower limbs and consists of the individual, starting from a sitting position, getting up from a chair without armrests. Equipment used for this test was a chair (with back, without armrests and a seat height of $43 \mathrm{~cm}$ ) and a Model SW 50 timer (Cassio, Japan). During the test, the chair remained leaning against a wall. The test began with the individual seating on the chair with his back straight, feet shoulder width apart, and arms crossed at breast height. The participant then stands up, using only the lower limbs, and returns to a sitting position, repeating this sequence as many times as possible in 30 seconds. Prior to the first assessment, the evaluator demonstrated the test to the participants. Afterwards, the patients performed two trials to allow familiarization with the procedure. In the actual tests, the greatest number of correctly performed repetitions in $30 \mathrm{sec}-$ onds was recorded for each patient. When reaching the 30 seconds mark, if the participant was in the middle of an attempt, this attempt was still included/recorded. ${ }^{13}, 14$

\section{BALANCE Test}

The balance test assesses the risk of falls using the Berg Balance Scale, according to the model of Shumway-Cook et al. 15 These tests were chosen because they are functional, easy to apply, cost effective, and have been validated and internationally accepted. ${ }^{11,16}$

The Berg Balance Scale serves several purposes, such as the quantitative description of functional balance; the risk factor assessment of loss of independence and falls; and to determine the effectiveness of interventions in clinical exercises and research. The scale evaluates static and dynamic balance, based on 14 common items of daily life, such as reach, turn, standing up and standing. The maximum score that can be achieved is 56 points. This test was applied in accordance with the procedures described by the authors who translated the test to Portuguese and adapted the test for its use in Brazil. ${ }^{16}$

The model of Shumway-Cook et al.,15 which established the relationship between the Berg Balance Scale and the risk of falls (10-100\%), was used for quantitative prediction of the risk of falls. With this model, fullscale sensitivity was $91 \%$ and the specificity $82 \%$. The probability of correct prediction increases in a non-linear fashion with decreasing score on the Berg Balance Scale. Each one-point decrease in the range of 56 to 54 points is associated with an increased risk of falls of 3 to $4 \%$. From 54 to 46, one-point changes are associated with $6-8 \%$ increased risk, and below 36 points the risk of falls quickly approaches $100 \% .^{15}$

\section{EDSS}

Neurological deficiency and disability was determined by the Functional Systems and EDSS proposed by Kurtzke. ${ }^{10}$ The EDSS is a neurological disability measure consisting of 20 intervals of " 0.5 " point, where " 0 " indicates normal neurological examination, "5.5" indicates ability to walk without aid or rest for at least 100 meters and "10" means death due to MS. For those scoring less than " 8 " on the EDSS, the classification is based on mobility and neurological evaluation focused on eight functional systems (Functional Systems): visual, pyramidal, sensory, cerebellar, sphincter, brain, 
brainstem and others. Scores from 0 to 3.0 (light) would represent minimal losses in terms of walking. Scores from 3.5 to 5.5 (moderate) indicate that the person can probably walk $100 \mathrm{~m}$. At scores of "6.0 to 7.5" (high) the person has much difficulty with activities of daily living, and from scores of " 8.0 " the person is likely restricted to bed (very high disability) (Cutter et al. 1999; Hobart et al. 2000). Scoring of " 8.5 to 9.5 " is based on self-care functions. ${ }^{10}$ Despite emphasizing movement and despite problems with standardization, sensitivity, reliability and inter-tester variability, this is still the most widely used measure in clinical trials, which include people with MS.

\section{Evaluation of subjective perception of effort (OMNIScale)}

\section{INTENSITY CONTROL}

The Scale of Perceived Exertion (OMNI) was used according with the procedure adopted by Lagally and Robertson 18 and Gearhart et al. ${ }^{19}$ Instructions were carried out using pictures to describe the perception of effort during the familiarization and training sessions. The effort level was marked on a scale of "extremely easy" (0) to "extremely difficult" (10), with the participant pointing to the number corresponding to the intensity of exercise. The strength-training load was adjusted during the intervention to fit the recommended OMNI Scale values of 6-8.

\section{FAMILIARIZATION}

After the individuals had filled in the questionnaires, two familiarization sessions were made where the exercises were demonstrated and the OMNI Scale was explained to them. During the familiarization, instructions were given on how to use the scale with figures (mentioned above), which would be used during the intervention. The scale was presented to the participants during each strength training session, and they were requested to indicate a numerical value on the scale corresponding to their perceived exertion at that moment.

\section{PROCEDURES}

The tests were applied before the start of the physical activity program (pre-intervention) and after 12 weeks (post-intervention). Between pre-intervention and postintervention, EG underwent the aquatic exercise program and the CG did not participate in any specific physical activity, as confirmed in the post-intervention interviews.

The activities were carried out three times a week, in sessions lasting 45-60 minutes in the period from 07:00 to 19:00 hours. The training sessions consisted of a warming up exercises out of the water (walking) and activities in the aquatic environment, such as walking exercises in the pool, various movements and exercises with specific equipment and swimming.

The sessions were composed by walking out of the water (warming up) (5-10 minutes), walking in chesthigh water level (sternum) (5-10 minutes), water bicycle using the noodle (5-10 minutes), exercises for the upper and lower limbs (5-10 minutes), breathing exercises (5 minutes), swimming (10 minutes) and a recovery period (5 minutes).

\section{Statistical analysis}

In this study, data were reported as mean \pm standard deviation. Normality of the data was verified using the Shapiro-Wilk Test, given the sample size. A two-way ANOVA, using "moment" and "group" as categorical variables (each with two levels; pre- and post-intervention, and $\mathrm{CG}$ and $\mathrm{EG}$ respectively), was used to assess changes in the physical condition of the participants. Afterwards, Tukey HSD post-hoc tests were performed to determine if there were differences between groups at each moment (pre- and post-intervention) and if there were changes within the groups after 12 weeks of intervention. For these analyses, a significance level of $\mathrm{P} \leq 0.05$ was used. To verify the effect size, Cohen's $\mathrm{f}^{2}$ test was used, with adopted cutoff points from 0.02 to 0.15 indicating small effect, 0.16 to 0.35 indicating moderate effect size, and greater than 0.35 indicating large effect size. ${ }^{20}$ All analyses were conducted using the statistical software SPSS, version 20.0.

\section{Results}

Participants were assessed before and after the aquatic exercise training intervention (Table III).

There were significant differences $(\mathrm{P} \leq 0.05)$ in all Functional Measures of physical condition in post-intervention, when comparing EG with $\mathrm{CG}$. Effect size was large in the balance activities and in the averages for the tests Timed "Up and Go", Timed 7.62 Meter Walk and Getting up from a Sitting Position (lower limb strength). 
TABLE III.-Functional measures of physical condition pre- and post-intervention in the experimental (EG) and control (CG) groups.

\begin{tabular}{|c|c|c|c|c|c|c|}
\hline Test & EG pre & EG post & CG pre & CG post & $\mathrm{P}$ & Cohen's f ${ }^{2}$ \\
\hline Up and Go & $13.96 \pm 4.33$ & $9.54 \pm 3.81 *$ & $14.01 \pm 4.23$ & $14.17 \pm 4.54$ & 0.043 & 0.334 \\
\hline $7.62 \mathrm{~m}$ & $8.41 \pm 4.32$ & $6.91 \pm 4.44 *$ & $8.35 \pm 3.80$ & $8.36 \pm 4.12$ & 0.031 & 0.348 \\
\hline Lower limb strength & $12.12 \pm 3.11$ & $13.72 \pm 3.23 *$ & $12.33 \pm 3.54$ & $12.31 \pm 3.44$ & 0.042 & 0.323 \\
\hline Balance Test & $41.83 \pm 5.19$ & $44.61 \pm 5.22 *$ & $41.58 \pm 6.18$ & $41.44 \pm 6.13$ & 0.012 & 0.670 \\
\hline
\end{tabular}

*P $\leq 0.05$ (two-way ANOVA and Tukey HSD post-hoc test).

\section{Discussion}

Muscle weakness is a hallmark symptom of MS and is associated with fatigue, reduced functional capacity and increased disability. In this study, we hypothesized that individuals with MS would increase muscle strength and improve physical condition in response to a conventional twelve-week aquatic exercise training program.

This study demonstrates that the aquatic program for individuals with MS is capable of improving their physical condition. Hence, this work's results contribute in two significant ways to current knowledge. First, they strongly support the clinical recommendation of considering aquatic exercise programs for patients with MS. Second, this data suggests that the effect size of improvement in the balance test is significantly greater after 12 weeks of aquatic exercise, when compared with the beginning of the training program. These results show the importance of aquatic exercise training for the studied group, since the loss of balance in MS patients restricts their daily activities and is responsible for frequent falls, which may cause injuries to the patients. ${ }^{21}$

In this sense, therapeutic exercise (aerobic fitness and muscle strength training) and physical therapy (range of motion, muscle activity, toning, coordination, and balance) are therapeutic elements of paramount importance in MS. ${ }^{22}$ They accomplish three major objectives inherent to physical activity, emphasizing the ease in performing tasks, maintaining or increasing physical condition and increasing aerobic condition. ${ }^{23}$

EG patients showed an improvement in the Timed "Up and Go" Test $(13,96 \pm 4,33$ to 9,54 $\pm 3,81, \mathrm{P}=0.043)$ after the water training program. Several studies have conducted the Timed "Up and Go" test. Some studies observed no change in the Timed "Up and Go" Test, ${ }^{24,25}$ with one of the studies showing a tendency $(\mathrm{P}=0.09)$ for a $13 \%$ improvement. 25 Others studies observed improvements in the Timed "Up and Go" Test of 8\% 26 and $9 \%,{ }^{27}$ corroborating the results of this study. The afore- mentioned functional tests that require more strength to perform the tasks generally show better improvements than the short and long walking tests.

Results indicate that balance in EG patients improved significantly $(41.83 \pm 5.19$ to $44.61 \pm 5.22, \mathrm{P}=0.012)$ after the aquatic exercise program, according to the Berg Balance Scale and the Timed "Up and Go" Test. Similar results were obtained by various authors, in which the application of an aquatic exercise program increased the balance in special groups. ${ }^{28,29}$ The authors are unanimous regarding the recommendation of aquatic exercises for individuals with increased fear and risk of falling. ${ }^{28,} 29$

In relation to the Timed 7.62 Meter Walk Test, improvements were observed in EG, resulting in a reduction in the walking/running time $(8.41 \pm 4.32 \mathrm{~s}$ to $6.91 \pm 4.44 \mathrm{~s}$ ). Testing for the ability to walk is based on its association with the disease's progression ${ }^{30}$ and it is considered an important personal function ${ }^{31}$ with profound implications for independence, quality of life, and daily-life activities of many patients. 32 Hence, the results of this walking performance test can indicate a promising clinical outcome for MS patients and, subsequently, has been receiving more attention. ${ }^{33}$

Another perspective on identifying the appropriate duration of walking performance tests might involve considering physiological variables such as the rate of oxygen consumption $\left(\mathrm{VO}_{2}\right)$. For example, there is abundant evidence in health controls that $\mathrm{VO}_{2}$ increases in a curvilinear manner over the initial 2-3 minutes of submaximal exercise, until reaching a plateau or "steadystate" that is maintained over the remainder of submaximal exercise. ${ }^{34,35}$

Regarding the lower limb strength, evaluated with the Getting up from a Sitting Position Test, there was significant improvement $(12.12 \pm 3.11$ to $13.72 \pm 3.23$, $\mathrm{P}=0.042)$ in the EG. This result may be related to the need for overcoming the water's resistance, since it affects speed and hampers movement. Hence, performing a movement pattern in the water will require more 
strength from the individual than performing the same exercise out of the water. ${ }^{36}$ Furthermore, movements increase the turbulence of the water, leading to a constant search for balance. Therefore, there is increased demand of leg strength for maintaining the standing position within the aquatic environment. ${ }^{36}$

\section{Conclusions}

Thus, it can be concluded that the water exercises tend to be beneficial for people affected by MS, improving their lower limb muscle strength, walking, sitting and standing. Furthermore, the effect size tends to be larger in physical traits related with balance. Thus, aquatic exercise stands as an important tool for maintaining and improving the physical condition of MS patients.

\section{References}

1. Kantarci O, Wingerchuk D. Epidemiology and natural history of multiple sclerosis: new insights. Curr Opin Neurol 2006;19:248-54.

2. Compston A, Coles A. Multiple sclerosis. Lancet 2002;359:1221-31.

3. Branas P, Jordan R, Fry-Smith A. Treatments for fatigue in multiple sclerosis: a rapid and systematic review. Health Technol Assess 2000;4:1-61.

4. Rietberg MB, Brooks D, Uitdehaag BM. Exercise therapy for multiple sclerosis. Cochrane Database Syst Rev 2005;25:CD003980

5. Heesen C, Romberg A, Gold S. Physical exercise in multiple sclerosis: supportive care or a putative disease-modifying treatment. Expert Rev Neurother 2006;6:347-55.

6. American Physical Therapy Association. Guide to physical therapist practice. Part 1: A description of patient/client management. Part 2 . Preferred practice patterns. American Physical Therapy Association. Phys Ther 1997;77:1160-656.

7. Guthrie TC, Nelson DA. Influence of temperature changes on multiple sclerosis: critical review of mechanisms and research potential. Neurol Sci 1995;129:1-8.

8. Motl RW, Mcauley E, Snook EM. Physical activity and multiple sclerosis: a meta-analysis. Mult Scler 2005;11:459-63.

9. Weikert M, Dlugonski D, Balantrapu S, Motl RW. Most common types of physical activity self-selected by people with multiple sclerosis. Int J MS Care 2011;13:16-20.

10. Kurtzke JF. Rating neurologic impairment in multiple sclerosis: an expanded disability status scale (EDSS). Neurology 1983;33:144452.

11. Podsiadlo D, Richardson S. The timed "Up \& Go": a test of basic functional mobility for trail elderly persons. J Am Geriatr Soc 1991;39:142-8.

12. Cutter GR, Baier ML, Rudick RA. Development of a multiple sclerosis functional composite as a clinical trial outcome measure. Brain 1999;122(Pt5):871-82.

13. Rikli R, Jones J. Development and validation of a functional fitness test for community-residing older adults. J Aging Phys Activ 1999;7:129-61.
14. Rikli R, Jones J. Functional fitness normative scores for communityresiding older adults, ages 60-94. J Aging Phys Activ 1999;7:16281.

15. Shumway-Cook A, Baldwin M, Polissar NL. Predicting the 21, probability for falls in community-dwelling older adults. Phys Ther 1997;77:812-9.

16. Miyamoto ST, Lombardi Junior I, Berg KO. Brazilian 19. Version of the Berg balance scale. Braz J Med Biol Res 2004;37:1411-21.

17. Hobart J, Freeman J, Thompson A. Kurtzke scales revisited: the application of psychometric methods to clinical intuition. Brain 2000;123(Pt 5):1027-40.

18. Lagally K, Robertson RJ. Construct validity of the OMNI resistance exercise scale. J Streng Cond Res 2006;20:252-6.

19. Gearhart Jr PF, Lagally KM, Riechman SE. Strength tracking using the OMNI resistance exercise scale in older men and women. J Streng Cond Res 2009;23:1011-5.

20. Grissom RJ, Kim JJ. Effect sizes for research: A broad practica aproach. Psycology Press: New York; 2005.

21. Cattaneo D, Jonsdottir J, Zocchi M. Effects of balance exercises on people with multiple sclerosis: a pilot study. Clin Rehabil 2007;21:771-81.

22. Motl RW, McAuley E, Snook EM. Physical activity and quality of life in multiple sclerosis: intermediary roles of disability, fatigue, mood, pain, self-efficacy and social support. Psychol Health Med 2009;14:111-24.

23. Döring A, Pfueller CF, Paul F. Exercise in multiple sclerosis - an integral component of disease management. The EPMA Journal 2012;3:2.

24. Broekmans T, Roelants M, Feys P. Effects of long-term resistance training and simultaneous electro-stimulation on muscle strength and functional mobility in multiple sclerosis. Mult Scler 2011:17:468-77.

25. DeBolt LS, McCubbin JA. The effects of home-based resistance exercise on balance, power, and mobility in adults with multiple sclerosis. Arch Phys Med Rehabil 2004;85:290-7.

26. Sabapathy NM, Minahan CL, Turner GT Comparing endurance- and resistance-exercise training in people with multiple sclerosis: a randomized pilot study. Clin Rehabil 2010;25:14-24.

27. Schwid SR, Thornton CA, Pandya S. Quantitative assessment of motor fatigue and strength in MS. Neurology 1999;53:743-50.

28. Booth CE. Water exercise and its effects on balance and gait to reduce the risk of falling in older adults. Activities, Adaptation and Aging 2004; $28: 45-57$

29. Devereux K, Roberston D, Briffa NK. Effects of a water-based program on women 65 years and over: a randomized controlled trial. Aust J Physiother 2005;51:102-8.

30. Goldman MD, Motl RW, Rudick RA. Possible clinical outcome measures for clinical trials in patients with multiple sclerosis. Ther Adv Neurol Disord 2010;3:229-39.

31. Larocca NG. Impact of walking impairment in multiple sclerosis: perspectives of patients and care partners. Patient 2011;4:189-201.

32. Van Asch P. Impact of mobility impairment in multiple sclerosis 2-patients' perspectives. Eur Neurol Rev 2011;6:115-120.

33. Butland RJ, Pang J, Gross ER. Two-, six-, and 12-minute walking tests in respiratory disease. Br Med J 1982;284:1607-8.

34. Savci S, Inal-Ince D, Arikan H. Six-minute walk distance as a measure of functional exercise capacity in multiple sclerosis. Disabil Rehabil 2005;27:1365-71.

35. Motl RW, Suh Y, Dlugonski D. Oxygen cost of treadmill and overground walking in mildly disabled persons with multiple sclerosis. Neurol Sci 2011;32:255-62.

36. Kura GG, Ribeiro LSP, Niquetti R. Level of physical activity, BMI and static muscular strength rates among elderly women engaged in aerobics and gymnastics. Braz J Sci Hum Aging 2004;1:30-40.

Conflicts of interest.-The authors certify that there is no conflict of interest with any financial organization regarding the material discussed in the manuscript. Article first published online: April 28, 2017. - Manuscript accepted: April 11, 2017. - Manuscript revised: March 2, 2017. - Manuscript received: October 30, 2016. 